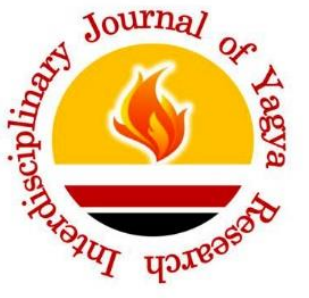

\title{
INTERDISCIPLINARY JOURNAL OF YAGYA RESEARCH
}

Peer Reviewed Research Journal

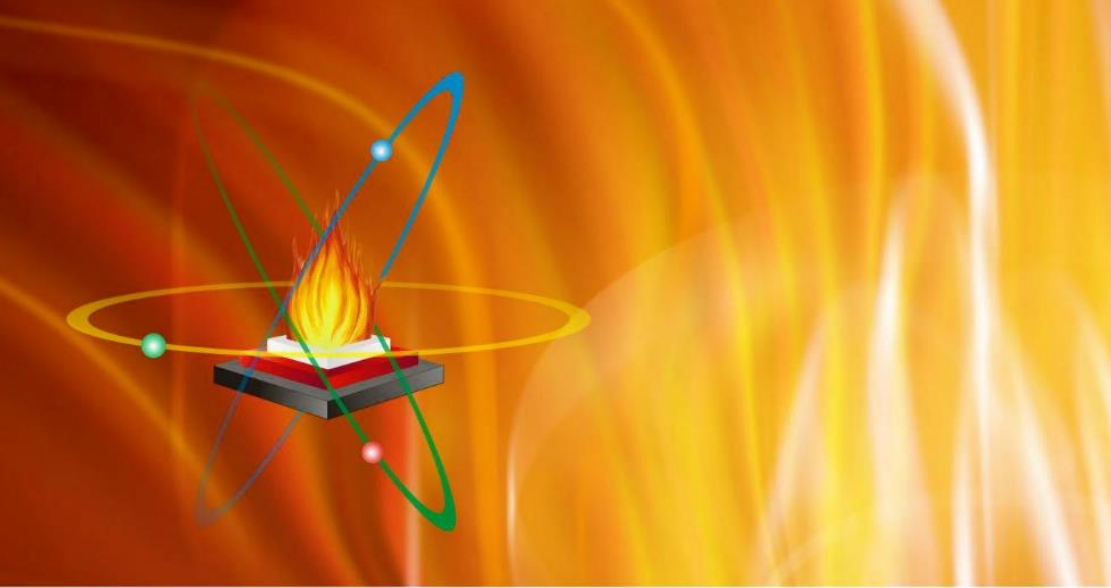




\title{
Yagya Therapy as supportive care in cancer patients improved quality of life: Case studies
}

\author{
Alka Mishra $^{*}$, Lalima Batham ${ }^{2}$, Vandana Shrivastava ${ }^{3}$ \\ ${ }^{1}$ Assistant Professor, Department of Yoga and Health, Dev Sanskriti Vishwavidyalaya, Haridwar \\ ${ }^{2}$ Volunteer, Center for Ayurveda Studies, Dev Sanskriti Vishwavidyalaya, Haridwar \\ ${ }^{3}$ Associate Professor, Department of Yoga and Health, Dev Sanskriti Vishwavidyalaya, Haridwar \\ * Corresponding author: Alka Mishra. Email- alka.mishra@dsvv.ac.in
}

\begin{abstract}
Cancer is becoming leading cause of death around the world. India has limited infrastructure and facility to fight the disease. In addition, side effects of current standard therapies like chemotherapy and radiation therapy severely hamper the quality of life (QOL) of patients. Alternative supportive therapies are a dire need, not only to reduce current therapeutic burden, but also to reduce the side effects, and deteriorating QOL of cancer patients. Yagya Therapy is an ancient Vedic therapeutic model, which allows pulmonary inhalation of medeicinal-smoke of multiherbs combination, generated through its oblation in fire, along with the chanting of mantras. The study attempted to evaluate QOL of life of three cancer patients (breast cancer, mouth cancer and chronic myeloid leukemia), who were prescribed to inhale medicinal-smoke generated using specifically prepared multi-herbs combination as part of Yagya Therapy by Center for Ayurveda Studies at Dev
\end{abstract}

Sanskriti Vishwavidyalaya. Patients continued their normal regime of allopathic treatment and used Yagya Therapy as supportive care. They were assessed for QOL using self-prepared 10-scale questionnaire. All three patients reported improvement in their QOL after taking Yagya Therapy for 12, 7 and 2 months, respectively. Averages of $\%$ improvement in all available individual conditions on 10-scale questionnaire, including physical and psychological complaints were $75 \%, 41.67 \%$, and $40 \%$, respectively. The study indicated the potential of Yagya Therapy using specific multi-herbs herbal preparation as supportive care for improving QOL of cancer patients taking standard allopathic treatments.

Keywords. Yagya Therapy, Cancer, Quality of life, herbal medicinal smoke 


\section{Introduction}

Cancer is among leading cause of death in the world, which is expected to rise about $70 \%$ in next 20 years as per report of WHO 2014 (1). Along with the rate of cancer increasing in world, predictions about rate of increase in cancer patients in India are also alarming. According to International Agency for Research on Cancer, India's burden of cancer will be 1.7 million by 2035, which will be double of that in 2012 (2).

Though immunotherapy and targeted therapy are emerging for cancer treatment, current conventional therapeutic options for cancer treatments are chemotherapy, radiation and surgery (3), which are accompanied by many other supplementary and alternative therapies (4). In addition, for India, as being a developing country, there are very limited resources for cancer treatment as compared to the prevailing burden of cancer (2), which also demands cost-effective, alternative therapies. Besides, chemotherapy has issues such as toxicity, drugresistance, limited efficacy, poor survival rate, and recurrence of cancer (5). Chemotherapy has several issues such as poor quality of life, poor performance status, worsening of mood states, imbalance in blood components and has several side effects, such as nausea, vomiting, fatigue, etc. (6). Effective adjunct therapies, which reduce these side effects of chemotherapy, improve patients' quality of life, and balance blood physiological condition, psychological and emotional mood states, are critically needed, and are being continuously explored.

Role of herbal intake as supportive therapy in cancer patients to improve quality of life, mood states is previously known. Various plant extracts or their derivatives are previously shown to be effective as adjunct therapy in combination with chemotherapy in all types of cancer patients. Herbal medicine intake along with chemotherapy has been shown to reduce side effects of chemotherapy, improve quality of life and also increase sensitivity of chemotherapy (4), (7). Herbal preparations, as supportive therapy to chemotherapy taking patients, has been effectively shown to relieve stress and anxiety, balance emotional instability, improve quality of life, reduce side effects, balance complete blood count (i.e. removing myelosuppression) and lipid profile for various types of cancer patients (8).

One method to effectively administer herbs into systemic circulation is Yagya Therapy. Yagya Therapy or Yagyopathy is an ancient Indian method of herbal inhalation therapy that allows for the pulmonary administration of herbs (9-10). Previously, it has been published that in the process of Yagya, coarse powder (havan samagri) made up of dry plant-medicines, as well as selected nutritious and aromatic substances, undergoes transformation into vapor phase, sublimation or decomposition by gradual heating; these phytomedicines spread along with the volatile substances and gases released by the slow and controlled combustion process in Yagya fire. Medicinal phytochemicals, vapors of some essential oils and certain other volatile healthy constituents released in this process impart therapeutic advantage (11-12).

Pulmonary inhalation of herbal medicinal- fumes generated in Yagya is effective, and cost efficient novel approach and has been shown to increase quality of life and/or diseased condition in mental patients (13), HIV patients (14) in TB patients (15). By providing dual advantage, i.e. exposure to medicinal-fumes of multiple herbs and efficient pulmonary administration (16), (17), Yagya therapy can be an effective methodology as supportive care in cancer patients taking chemotherapy treatments. Hence, it is hypothesized that medicinal-fumes generated in Yagya using special herbal preparation can be implied as supportive care for increasing quality of life, increasing performance status, balancing mood states, and reducing side effects in cancer patients taking chemotherapy.

In the present study, a herbal-preparation (havan samagri), which is prepared at the Center for Ayurveda Studies (CAS) at Dev Sanskriti Vishwavidyalaya, Haridwar since past several years, was prescribed to patient to be taken as per the 
protocol described in the methods section. This herbal preparation contains carefully selected more than 40 herbs based on their taxonomy classification and potential properties useful in the treatment of cancer. The study attempts to present available feedback from cancer patients treated with Yagya Therapy using the aforesaid herbal preparation.

\section{Methods}

\section{Procedure of Yagya and herbal preparation intake}

Patients were advised to follow standard protocol of Yagya at home described by the Center for Ayurveda Studies (CAS). Briefly, the procedure includes doing Shatkarma (Pavitrikaranam, achaman, shikhavandanam, nasya, prithvi pujanam), chandandharanam, Guru Aavahan, 24 Gayatri Mantrahuti using hawan samagri, and pranayama (18). Patients were advised to use copper pot, mango sticks or otherwise prescribed by CAS, ghee (clarified butter made from indigenous cow's milk), and herbal preparation (hawan samagri) prescribed by CAS. Other details of the prescribed methodology are given in Table 1.

\section{Herbal mixture (Hawan samagri) preparations}

Since past several years, the Center for Ayurveda Studies (earlier Center of Holistic Health Management), Department of Yoga and Health at Dev Sanskriti Vishwavidyalaya, Haridwar, Uttarakhnad has been prescribing Yagyopathy, wherein different herbal preparations of Ayurvedic plant medicines (hawan samagri) have been made in-house for various diseases including cancer. The hawan samagri for cancer treatment consisted of more than 40 herbs (9).

No metal is used in the herbal preparations. All ingredients were well identified by taxonomist (19), were non-toxic, and could be useful in the management of cancer, and the associated physical and mental symptoms and disorders. Some of them are : Tulasi (Ocimum tenuiflorum) (20), Saptaparni (Alstonia Scholaris) (21), Aswagandha (Withania somnifera) (22), Harada (Terminalia chebula) (23), Mulaithi (Glycyrrhiza Glabra Bois) (24), Punarnava (Boerhavia diffusa) (25), etc. Along with hawan samagri prepared for cancer treatment, patients were prescribed common purpose hawan samagri. Both were mixed in $3: 1$ ratio.

\section{Patient Evaluation}

Followup form containing 10-scale QOL questionnaire was prepared. Response of the patients was also collected for another general questionnaire, which contained demographics and followup of prescribed method of Yagya Therapy. The entries of the QOL questionnaire were assessed on a 5 point scale i.e. $0 \%, 25 \%, 50 \%, 75 \%, 100 \%$ asking for improvement in different conditions/complaints felt after application of Yagya Therapy. Patients' prior consents were taken to use their data for research publication, without revealing their identity.

\section{Results}

The study included 3 case studies of cancer patients who had voluntarily filled up the QOL questionnaire during their visit at Center for Ayurveda studies. Three Patients suffering from breast cancer, mouth cancer and chronic myeloid leukemia, respectively, who were taking Yagya Therapy along with allopathic treatment, were assessed using the questionnaire (Figure 1). At the time of the preparation of the manuscript, only 3 individuals' QOL questionnaire had been collected at Center of Ayurveda Studies, which have been reported herewith. Overall Yagya Therapy as supportive care improved QOL, both physically (body pain, breathing difficulties, etc.) and mentally (stress, sadness, etc.) (Figure 2 - 2A, 2B, 2C).

\section{Patient 1 - breast cancer patient}

Patient 1 was diagnosed with breast cancer stage IV in Feb 2017 and started Yagya Therapy immediately along with standard allopathic treatment (Figure 1). Patient had continued with Yagya Therapy treatment for around 12 months (Table 1) at the time of QOL assessment. Meanwhile, patient had gone through other treatments such as radiation therapy, chemotherapy, and was taking hormone therapy at the time of the assessment.

The patient reported an overall improvement of $75 \%$ 
in her condition ever since she started taking treatment, which included various conventional treatments mentioned above, as well as Yagya Therapy. The calculated \% improvement (average of percentage improvement of individual conditions reported on 10-scale QOL questionnaire) was also $75 \%$ (Table 1). Patient indicated improvement in QOL - both physical and psychological conditions (Figure 2A). The patient diligently followed the prescribed condition for Yagya Therapy, i.e. small size room (10'X10'), proper dose of herbal preparation (30 gm), sufficient time for pranayama after oblation of herbs in the fire, etc. (Table 2). It is noteworthy that the patient has reported improvement in those conditions as well wherein the patients taking only conventional treatment experience deterioration, due to the known side effects of conventional therapies; this improvement may be attributed to the continuous supportive care of the Yagya Therapy.

\section{Patient 2 - mouth cancer patient}

Patient 2 was diagnosed with mouth cancer in July 2017 and started Yagya Therapy within a month after starting radiation therapy (Figure 1) and continued with Yagya Therapy after the completion of radiation therapy. Patient had been taking Yagya Therapy treatment for around 7 months (Table 1) up to the time of QOL assessment.

The patient reported an overall improvement of $25 \%$ in his condition ever since he started taking treatment, which included surgery and radiation therapy, as well as Yagya Therapy. The calculated \% improvement (average of percentage improvement of individual conditions reported on 10-scale QOL questionnaire) was $41.67 \%$ (Table 1). Patient indicated improvement in QOL - both physical and psychological conditions (Figure 2B). The patient followed the prescribed condition for Yagya Therapy, i.e. small size room (10'X15'), proper dose of herbal preparation (30 gm), sufficient time for pranayama after oblation of herbs in the fire, etc. (Table 2). It is noteworthy that the patient has reported improvement in those conditions as well wherein the patients taking only conventional treatment experience deterioration, due to the known side effects of conventional therapies; this improvement may be attributed to the continuous supportive care of the Yagya Therapy.

\section{Patient 3 - chronic myeloid leukemia patient}

Patient 3 was diagnosed with chronic myeloid leukemia around 14 years ago. He did not go through treatments such as radiation therapy, chemotherapy. He was prescribed for Veenat $400 \mathrm{mg}$ daily, but the exact starting time for this medication is not known. The patient started taking Yagya Therapy as supportive care (Figure 1) in December 2017, continued for about 1.5 months, and was not doing Yagya Therapy for some time because of lack of availability of havan samagri. The results reported by the patient are for the time duration when he was taking Yagya Therapy.

The patient reported an overall improvement of 50\% in his condition during the time he was taking Yagya Therapy. The calculated \% improvement (average of percentage improvement of individual conditions reported on 10-scale QOL questionnaire) was 40\% (Table 1). Patient indicated improvement in QOL both physical and psychological conditions (Figure 2C). Interestingly, the patient did not follow prescribed conditions for Yagya Therapy treatment; for example, he took Yagya Therapy on terrace instead of in a small room, and used less than 30 grams of herbs for doing Yagya Therapy, as well as preparing decoction (Table 2). It is noteworthy that after doing Yagya Therapy, the patient showed QOL improvement on several conditions. One major complaint of the patient before the start of the Yagya Therapy was loss of appetite, in which the patient reported $75 \%$ improvement after starting Yagya Therapy.

\begin{tabular}{llll}
\hline \% improvement & Patient 1 & Patient 2 & Patient 3 \\
Patient reported & $75 \%$ & $25 \%$ & $50 \%$ \\
Calculated & $75 \%$ & $41.67 \%$ & $40 \%$ \\
\hline
\end{tabular}

Table 1. Summary of percentage (\%) improvement in the quality of life of cancer patients taking Yagya Therapy as supportive care. 'Patient reported' \% improvement was a general feedback of patient regarding improvement felt after taking Yagya Therapy between $0 \%$ to $100 \%$. The calculated $\%$ improvement was the average of percentage improvement of individual conditions reported on 10-scale QOL questionnaire. 


\begin{tabular}{|c|c|c|c|}
\hline Assessment parameters & Patient 1 & Patient 2 & Patient 3 \\
\hline Cancer type & $\begin{array}{l}\text { Breast } \\
\text { cancer }\end{array}$ & $\begin{array}{l}\text { Mouth } \\
\text { cancer }\end{array}$ & $\begin{array}{l}\text { Chronic myeloid } \\
\text { leukemia }\end{array}$ \\
\hline Age & 45 & 44 & 63 \\
\hline Gender & Female & Male & Male \\
\hline Resident state (in India) & Maharashtra & Rajasthan & Bihar \\
\hline Number of times prescription refilled & 7 & 3 & 2 \\
\hline Date of follow-up & $24 / 3 / 18$ & $25 / 3 / 18$ & $22 / 2 / 18$ \\
\hline Number of time Yagya performed per day & 2 & 2 & 1 \\
\hline Number of times Kadha taken per day & 2 & 2 & 2 \\
\hline Pranayama performed per Yagya (min) & 30 & 30 & 15 \\
\hline Size of room (feet) & $10 \times 10$ & $10 \times 15$ & On terrace \\
\hline Herbal preparation used per Yagya (gram) & 30 & 30 & $<30$ \\
\hline Duration of Yagya therapy taken (months) & 12 & 7 & 2 \\
\hline $\begin{array}{l}\text { Yagya Therapy taken during } \\
\text { chemotherapy or radiation therapy }\end{array}$ & Yes & Yes & Not Applicable \\
\hline
\end{tabular}

Table 2. Demographics and follow up of prescribed method of therapy by cancer patients taking Yagya Therapy as supportive care.

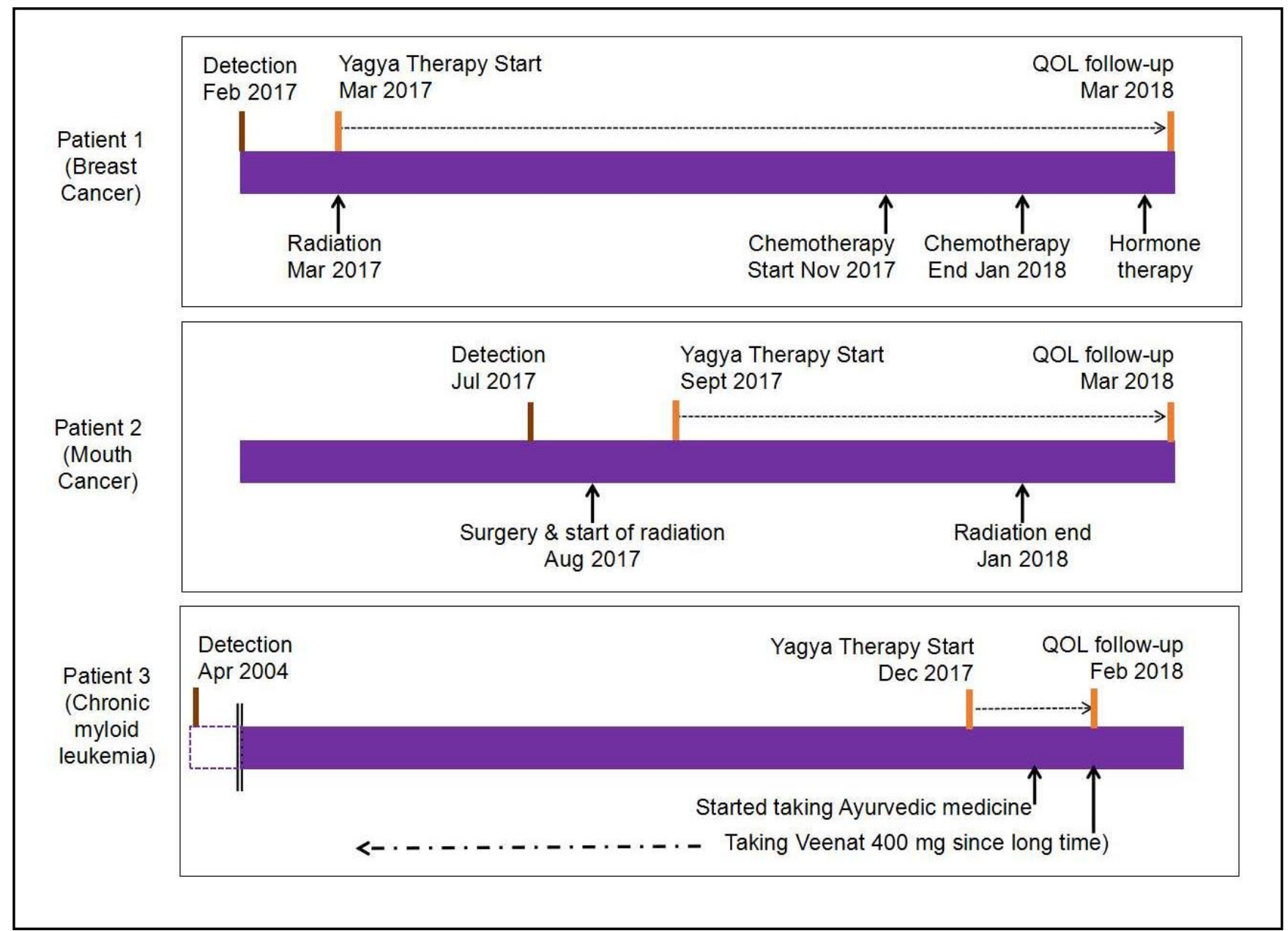

Figure 1. Treatment timeline of three cancer patients taking Yagya Therapy as supportive care. Timeline is shown for cancer detection, Yagya Therapy, allopathy treatment (chemotherapy, radiation therapy/other treatments) of cancer patients, who were assessed using QOL questionnaire. (QOL - Quality of life) 


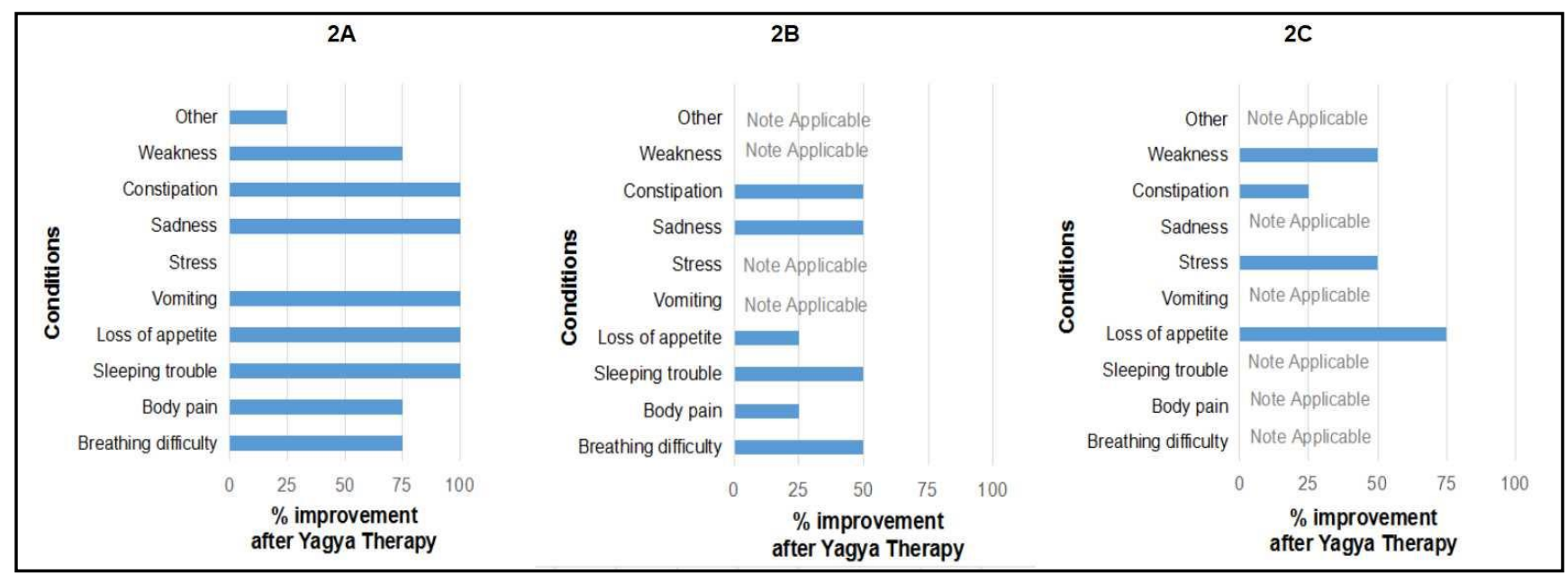

Figure 2. Quality of life of cancer patients taking Yagya Therapy as supportive care. Percentage improvement reported using 10-scale quality of life questionnaire by $(2 \mathrm{~A})$ breast cancer patient, $(2 \mathrm{~B})$ mouth cancer patient, $(2 \mathrm{C})$ chronic myeloid leukemia patient. $\mathrm{Y}$ axis is different conditions for which the assessment was made. $\mathrm{X}$ axis is the percentage (\%) improvement patient reported on 10 - scale questionnaire after taking Yagya Therapy as supportive care. A condition mentioned as 'other' in $2 \mathrm{~A}$ was numbness and tingling feeling in the right and left toes and fingers of breast cancer patient, while for $2 \mathrm{~B}$ and $2 \mathrm{C}$ no other condition was reported.

\section{Discussion}

The study indicated potential of Yagya Therapy as supportive or adjunct therapy for the cancer patients to improve QOL. The study reported 3 case studies of three different cancer types, who were given Yagya Therapy as supportive care. All 3 cancer patients showed improvement in their QOL on various conditions including physical and psychological parameters, indicating potential of this novel therapy as supportive care in cancer treatment.

One of the important aspect of Yagya Therapy for getting improved quality of life is the pulmonary inhalation of medicinal-smoke of the prescribed herbs. Herbs have been used extensively for supportive care in cancer patients in India and other countries (26). However, administration of multi-herbs through oral administration has limitations such as first pass metabolism of herbs and decreased patient capacity to take herbs orally during chemotherapy or other therapies (27). Yagya Therapy overcomes both of these limitations as it utilizes pulmonary inhalation as mode of drug administration.

In Yagya Therapy, the herbal preparation contained herbs, which were chosen based on careful review of Ayurvedic pharmacology, modern pharmacology, and scriptural indications $(9,22-25)$. Their aromatic volatile oil helps in the management of cancer. Utility of volatile oil in cancer patients is previously indicated (28-29).

One of the common complaint of cancer patients is weakness (Ramirez et al., 2009). In the Yagya Therapy, use of cow ghee is advantageous in this condition, as through inhalation it might be entered into systemic circulation. According to Indian scripture, the utilization of ghee in Yagya is meant to give strength to patient who otherwise cannot digest fat in diseased condition (30). Furthermore, lipid nanoparticles are shown to enhance drug delivery in modern research findings (31); hence, use of ghee in the Yagya Therapy might be helpful in the delivery of the phytochemicals present in the medicinal fumes of the Yagya Therapy. Further studies are needed to establish these probable beneficial effects of ghee in Yagya Therapy.

In the prescribed therapy by CAS, patients also took the Kadha (water decoction made using the herbal 
preparation given for the Yagya Therapy) along with the pulmonary inhalation of the medicinal fumes of the herbs. Besides, patients were also prescribed Gau Ark (distilled cow urine), to be taken once per day in the morning. These factors might also have contributed for the improvement in QOL.

In the present study, all 3 patients took Yagyopathy from 2 to 12 months along with modern therapies such as chemotherapy, radiation therapy, hormone therapy, etc. and reported notable benefits in QOL, indicating that Yagya Therapy is safe and compatible as adjunct therapy in cancer patients.

It is noteworthy that the present study was done in OPD (Out-Patient Department) setting wherein the patients were prescribed the therapy, and they were required to do Yagya at their home. Such a setting has obvious limitations with regards to following the prescribed procedure; however, the patients still reported notable benefits due to Yagya Therapy.

Thus, the present study shows the notable effectiveness of Yagya Therapy in the treatment of cancer patients as supportive care along with the conventional therapies. Further studies are needed to establish the mechanism and role of Yagya Therapy in cancer treatment.

\section{References}

1. Plummer M, de Martel C, Vignat J, Ferlay J, Bray F, Franceschi S. Global burden of cancers attributable to infections in 2012: a synthetic analysis. Lancet Glob Heal. 2016;4(9):e609-16. Available from: http://linkinghub.elsevier.com/retrieve/pii/S2214109X16301437

2. Mallath MK, Taylor DG, Badwe RA, Rath GK, Shanta V, Pramesh CS, et al. The growing burden of cancer in India: epidemiology and social context. Lancet Oncol. 2014;15(6):e20512. Available from: http://linkinghub.elsevier.com/retrieve/pii/S1470204514701159

3. Urruticoechea A, Alemany R, Balart J, Villanueva A, Viñals F, Capellá G. Recent advances in cancer therapy: an overview. Curr Pharm Des. 2010;16(1):3-10. Available from: http://www.ncbi.nlm.nih.gov/pubmed/20214614
4. Yin S-Y, Wei W-C, Jian F-Y, Yang N-S. Therapeutic applications of herbal medicines for cancer patients. Evid Based Complement Alternat Med. 2013:302426. Available from: http://www.ncbi.nlm.nih.gov/pubmed/23956768

5. Chabner BA, Roberts TG. Chemotherapy and the war on cancer. Nat Rev Cancer. 2005;5(1):65-72. Available from: http://www.ncbi.nlm.nih.gov/pubmed/15630416

6. Ramirez LY, Huestis SE, Yap TY, Zyzanski S, Drotar D, Kodish E. Potential chemotherapy side effects: what do oncologists tell parents? Pediatr Blood Cancer. 2009;52(4):497-502. Available from: http://www.ncbi.nlm.nih.gov/pubmed/19101994

7. Qi F, Li A, Inagaki Y, Gao J, Li J, Kokudo N, et al. Chinese herbal medicines as adjuvant treatment during chemo- or radiotherapy for cancer. Biosci Trends. 2010;4(6):297-307. Available from: http://www.ncbi.nlm.nih.gov/pubmed/21248427

8. Metri K, Bhargav H, Chowdhury P, Koka PS. Ayurveda for chemo-radiotherapy induced side effects in cancer patients. J Stem Cells. 2013;8(2):115-29. Available from: http://www.ncbi.nlm.nih.gov/pubmed/24698988

9. Brahmavarchas, editor. Yagya Chikitsa. 1st ed. Shri Vedmata Gayatri Trust, Shantikunj, Haridwar (Uttarakhand), 249411, India; 2010:1-368

10. Pandya P. Applied Science of Yagya for Health \& Environment. Shri Vedmata Gayatri Trust, Shantikunj, Haridwar (Uttarakhand), 249411, India; 2009:1-117. Available from: www.awgp.org

11. Joshi RR, Raghuvanshi M, Pandya P. Yagyopathy versus oral and iv drug administration: evaluation for pulmonary tuberculosis using compartment modeling. J Biol Syst. 2006;14(03):463-89. Available from: http://www.worldscientific.com/doi/abs/10.1142/S0218339006001 891

12. Raghuvanshi M, Pandya P, Joshi RR. In-vitro testing of an ethnobotanical inhalation therapy against pulmonary tuberculosis. Phytotherapie. 2009;7(5):243-9.

13. Sharma S. Yagya Chikitsa Dwara Manasik Swasthya Par Padane Vale Prabhav Ka Adhyayan (Hindi)(Dissertation). Dev Sanskriti Vishwavidyalaya, Shantikunj, Haridwar, Uttarakhand, India. 2009.

14. Sharma P, Khokhar CP, Manchanda SC, Sharma N. Yagya Therapy for Managing Inferiority \& Insecurity feeling of HIV + I AIDS Patients. Dev Sanskriti Interdiscip Int J. 2012;01:70-7.

15. Raghuvanshi M, Pandya P, Joshi RR. Yagyopathic Herbal Treatment of Pulmonary Tuberculosis Symptoms: A Clinical Trial. 
Altern Complement Ther. 2004;10(2):101-5. Available from: http://www.liebertonline.com/doi/abs/10.1089/1076280047739333 52

16. Hu X, Yang F, Liao Y. Pharmacokinetic considerations of inhaled pharmaceuticals for systemic delivery. Curr Pharm Des. 2016;22(17):2532-48

17. Mohagheghzadeh A, Faridi P, Shams-Ardakani M, Ghasemi Y. Medicinal smokes. J Ethnopharmacol. 2006;108(2):161-84

18. Sharma S, editor. Sankshipt Gayatri hawan vidhi (Hindi). Revision. Yug nirman yojana vistar trust, Gayatri Tapobhumi, Mathura; 2012. 1-49

19. Sharma P. Dravyaguna Vijnana - Volume II (Hindi). Chaukhambha Bharati Academy, Varanasi, Uttar Pradesh, India. 2001.

20. Baliga MS, Jimmy R, Thilakchand KR, Sunitha V, Bhat NR, Saldanha E, et al. Ocimum sanctum L (Holy Basil or Tulsi) and its phytochemicals in the prevention and treatment of cancer. Nutr Cancer. 2013;65(sup1):26-35. Available from: http://www.tandfonline.com/doi/abs/10.1080/01635581.2013.7850 10

21. Manjeshwar Shrinath Baliga. Alstonia scholaris Linn $\mathrm{R} \mathrm{Br}$ in the treatment and prevention of cancer: past, present, and future. Integr Cancer Ther. 2010;9(3):261-9. Available from: http://journals.sagepub.com/doi/10.1177/1534735410376068

22. Palliyaguru DL, Singh S V, Kensler TW. Withania somnifera: From prevention to treatment of cancer. Mol Nutr Food Res. 2016;60(6):1342-53. Available from: http://doi.wiley.com/10.1002/mnfr.201500756

23. Bag A, Bhattacharyya SK, Chattopadhyay RR. The development of Terminalia chebula Retz. (Combretaceae) in clinical research. Asian Pac J Trop Biomed. 2013;3(3):244-52. Available

from: http://linkinghub.elsevier.com/retrieve/pii/S2221169113600593
24. Wang ZY, Nixon DW. Licorice and cancer. Nutr Cancer. 2001;39(1):1-11. Available from: http://www.tandfonline.com/doi/abs/10.1207/S15327914nc391_1

25. Mishra S, Aeri V, Gaur PK, Jachak SM. Phytochemical, therapeutic, and ethnopharmacological overview for a traditionally important herb: Boerhavia diffusa Linn. Biomed Res Int 2014:808302. Available from: http:/www.hindawi.com/journals/bmri/2014/808302/

26. Richardson MA, Sanders T, Palmer JL, Greisinger A, Singletary SE. Complementary/Alternative Medicine Use in a Comprehensive Cancer Center and the Implications for Oncology. J Clin Oncol. 2000;18(13):2505-14. Available from: http://www.ncbi.nlm.nih.gov/pubmed/10893280

27. Kesarwani K, Gupta R, Mukerjee A. Bioavailability enhancers of herbal origin: an overview. Asian Pac J Trop Biomed. 2013;3(4):253-66. Available from: http://www.ncbi.nlm.nih.gov/pubmed/23620848

28. Ndao DH, Ladas EJ, Cheng B, Sands SA, Snyder KT, Garvin $\mathrm{JH}$, et al. Inhalation aromatherapy in children and adolescents undergoing stem cell infusion: results of a placebo-controlled double-blind trial. Psychooncology. 2010;3:247-254.

29. Potter P, Eisenberg S, Cain KC, Berry DL. Orange Interventions for Symptoms Associated With Dimethyl Sulfoxide During Stem Cell Reinfusions. Cancer Nurs. 2011;34(5):361-8. Available from: http://www.ncbi.nlm.nih.gov/pubmed/21372706

30. Brahmavarchas, editor. Yagya ka gyan vigyan (Pt. Shriram Sharma Acharya Vangmay 25). Akhand Jyoti Sansthan, Mathura 281003; 1994. Available from: www.literature.awgp.org

31. Pandya NT, Jani P, Vanza J, Tandel H. Solid lipid nanoparticles as an efficient drug delivery system of olmesartan medoxomil for the treatment of hypertension. Colloids Surfaces B Biointerfaces. 2018;165:37-44. Available from: http://linkinghub.elsevier.com/retrieve/pii/S0927776518300808 